Fronteiras - Revista Catarinense de História | https://periodicos.uffs.edu.br/index.php/FRCH/index ISSN 2238-9717 | n. 37, p. 291-296, jul.-dez./2021 | DOI: https://doi.org/10.36661/2238-9717.2021n37.12351

\title{
A canção latino-americana em questão
}

Igor Lemos Moreira ${ }^{1}$

GARCIA, Tânia da Costa. Do folclore à Militância: A canção latino-americana no século XX. São Paulo: Letra e Voz, 2021.

A obra Do folclore à Militância: A canção latino-americana no século $X X$, da historiadora Tânia da Costa Garcia, é resultado de sua tese de livre-docência apresentada à Universidade Estadual Paulista. Publicada em 2021 pela editora Letra e Voz, foi inicialmente lançada em inglês pela Lexington Books (2019), com o título: The Latin American Songbook in the Twentieth Century: From Folklore to Militancy. Docente da UNESP, Garcia dedica-se, desde a pós-graduação, a pesquisar temáticas como identidades nacionais, canção engajada, meios de comunicação e cultura popular. Ao longo de sua trajetória publicou $O$ "it verde e amarelo" de Carmen Miranda (1930-1946), pela Annablume/FAPESP em 2004, e foi organizadora das coletâneas Música popular: História, memória e identidades e Música e Política: um olhar transdisciplinar, ambas pela editora Alameda em 2013 e 2015, respectivamente. A longa trajetória como pesquisadora na área de música e cultura popular é apresentada de forma resumida na obra, que reúne resultados de suas pesquisas nos últimos anos que envolveram a passagem por instituições brasileiras, britânicas e argentinas.

Organizado em duas partes, divididas em nove capítulos, Do folclore à Militância, tematiza a trajetória da canção popular midiática no Brasil, Argentina e Chile, com ênfase na dimensão folclórica, sendo alguns dos textos versões revisadas e/ou expandidas de publicações anteriores. Além dos capítulos, o livro conta com um prefácio escrito por Mariana Villaça e um texto introdutório sobre a música como objeto de investigação do(a) historiador(a), fundamental para compreender o percurso desenvolvido pela autora. Neste capítulo teórico, Garcia apresenta um panorama geral de perspectivas historiográficas brasileiras que mobilizaram a canção como documento/objeto/tema, destacando os principais perfis envolvidos e indicando possibilidades teórico-metodológicas aplicáveis. A perspectiva aplicada em seu estudo, defende que a análise da canção como produção cultural é indissociável de suas condições históricas de elaboração “e recepção, o que envolve desde as motivações do compositor, os interesses de mercado, o impacto de múltiplas tecnologias a política cultural em voga, até os espaços de sociabilidade daqueles que a promovem e consome." (GARCIA, 2021, p. 29). Desta forma, as produções cancionais estão diretamente ligadas ao seu contexto e a temporalidade na qual se inscreve,

\footnotetext{
${ }^{1}$ Doutorando em História. Universidade do Estado de Santa Catarina. Bolsista CAPES-DS. Brasil. E-mail: igorlemoreira@gmail.com
} 
Fronteiras - Revista Catarinense de História | https://periodicos.uffs.edu.br/index.php/FRCH/index

sendo esse um dos principais focos possíveis de uma perspectiva historiográfica da música. Neste sentido, a obra aproxima-se do trabalho Pensando a música a partir da América Latina (2016), de Juan Pablo González, que defende a canção enquanto um processo contínuo e inscrito no meio social em que foi produzida, executada e significada.

Tal entendimento possibilita a expansão documental ao(a) pesquisador(a) que pode envolver em seu estudo não somente a forma-canção, mas documentos escritos, visuais, midiáticos, orais, biográficos, entre outros. A abordagem de Garcia defende o uso da canção não apenas como produção estética e/ou narrativa, mas enquanto criação artística que circula em sociedade e cujos registros, ou marcas, são deixados em diferentes espaços, suportes e contextos. Em seu estudo, por exemplo, são mobilizados fonogramas em diferentes suportes, revistas periódicas, escritos biográficos e obras memorialistas e/ou historiográficas que lhe permitem construir um grande panorama da canção latino-americana no século XX, a partir do Cone Sul, com destaque ao período de 1940 a 1960.

A primeira parte da obra reúne sete capítulos em torno do eixo Do folclore aos meios de comunicação de massa: a canção popular como símbolo da nacionalidade. Ao longo dos textos, a autora aborda a relação estabelecida entre folclore e identidade nacional, detendo-se primeiramente Chile, para em seguida analisar o Brasil e a Argentina, sendo que este último país, vale ressaltar, é tematizado por quatro dos capítulos, com destaque ao contexto peronista no qual a produção cultural/musical foi instrumentalizada como possibilidade de formação nacional. Ao longo dos textos, Garcia demonstra o lugar da canção folclórica na constituição das identidades nacionais no início do século passado através dos estudos folclóricos, das políticas culturais, e das relações sociais estabelecidas. Desta forma, é abordada a dimensão do folclore através dos debates que a marcaram, e não propriamente das práticas, buscando entender justamente as iniciativas e processos de folclorização que marcaram estes países.

Destaca-se na abordagem empreendida, e nas hipóteses levantadas, o campo intelectual envolvido. Ao longo dos capítulos, Garcia analisa diferentes revistas especializadas em música e cultura, com destaque a: Revista Musica Chilena (Chile), Revista de Música Popular (Brasil), Revista do Rádio (Brasil) e Mundo Radial (Argentina). O uso de impressos, articulado a análise cancional, procura discutir as estratégias empreendidas em cada nação para legitimar e construir uma identidade nacional que mobilizasse as práticas consideradas "tradicionais". No caso chileno (1940-1960), por exemplo, percebe-se o processo de nacionalização do folclore pelos órgãos de Estado e veículos de comunicação focados na população mais jovem. No Brasil, esse processo foi distinto pois, nesse mesmo contexto, havia uma diferenciação entre a canção popular e a canção folclórica, que não seriam sinônimos. Ao longo da década de 1950, em 
Fronteiras - Revista Catarinense de História | https://periodicos.uffs.edu.br/index.php/FRCH/index

especial através da Revista do Rádio, Garcia destaca o lugar ocupado pelo Samba, assim como compara esse processo com a presença da canção folclórica na mídia radiofônica.

O caso Argentino merece um destaque específico, tendo em vista que este é o principal país abordado pela primeira parte do livro. Como aponta Garcia, os debates em torno do folclore argentino, em especial o universo cancional, marcou o processo de modernização do país e as relações entre campo e cidade. Nos anos 1940, afirma a autora, uma série de políticas públicas foram instauradas na Argentina procurando lidar com o êxodo rural, sendo que "suas referências culturais, durante o governo de Juan Domingo Perón, foram formatadas e veiculadas pelos meios de comunicação, controlados, nestes anos, pela subsecretaria de Informações e Imprensa, que organizava a propaganda estatal e atuava também como censora." (GARCIA, 2021, p. 87). A figura do Gaúcho foi retomada neste contexto, sendo este um ponto de intersecção que existiu entre o século XX e o XIX na ocasião de retomada de alguns dos principais escritos fundacionais do país, como Martín Fierro e a geração de 37.

Segundo a autora, no contexto peronista foi fundamental a atuação da imprensa e dos veículos de comunicação que atuaram diretamente na popularização de gêneros musicais considerados folclóricos, denominados de música criolla, como valses criollos, zamba, crifras, tonadas, milangas e gatos, e que por sua vez valorizavam um "universo folclórico como representação do nacional." (GARCIA, 2021, p. 101). Ainda neste debate, Garcia atenta para como o processo de inserção das culturas folclóricas argentinas no circuito dos meios de comunicação, em especial das indústrias fonográficas e da massificação da cultural, não foi isento de tensões, afirmando que a intersecção entre campo e da cidade criou um entre-lugar da produção cancional argentina na metade do século XX. Essa leitura, baseada nas ideias de Homi Bhabha, atenta para uma tentativa de formação de identidade nacional que mobilizava experiências passadas, presentes e futuras e que não era coesa ou homogênea. Como estudo de caso, a autora discute nesta primeira parte o caso do músico argentino Atahualpa Yupanqui, considerado por muitos como um dos primeiros artistas que influenciaram a formação da Nova canção e que em sua obra reverberava a relação campo(passado)-cidade(presente).

A segunda parte da obra, A canção militante na América Latina, é composta por dois capítulos que adotam a perspectiva comparativa para analisar a "canção militante", como define a autora, ao longo dos anos 1960. Segundo a autora, a emergência de músicas engajadas, em especial em contextos de autoritarismos e ditaduras, marcou os anos 1960, sendo também influenciada pelos processos de mundialização da cultura. Segundo a autora, "sua produção e difusão beneficiaram-se não só de avanços tecnológicos como também de redes pré-existentes sustentadas por conexões político-ideológicas, que orientaram sua forma de produção e 
Fronteiras - Revista Catarinense de História | https://periodicos.uffs.edu.br/index.php/FRCH/index

consumo para além das fronteiras" (GARCIA, 2021, p. 133). Se, nas décadas passadas, o continente americano viveu um contexto atravessado pelas tentativas de integração latinoamericana, a década de 1960 marcou acirramentos e rupturas sociais.

Com as esquerdas latino-americanas assumindo um perfil cada vez mais radical, abandonando a ideia de "revolução em etapas", sob influência da Revolução Cubana e a derrota estadunidense e de exilados no Ataque a Baia dos Porcos, a arte latino-americana passou a reverberar os projetos socialistas em efervescência no Cone Sul. De acordo com Garcia, o "canto de protesto" na Argentina e no Chile foram perpassados pela articulação entre demandas do tempo vivido e a figura do cancioneiro folclórico que foi um projeto de construção ligado as políticas culturais nacionais. Por retomar as culturas folclóricas, a ideia de uma canção militante "incomodou" setores mais conservadores das sociedades chilena e argentina, tendo em vista que, para uma parcela da população, tais produções eram uma afronta a tradição nacional. No Brasil, a emergência da MPB teria sido particularmente interessante, segundo a autora, pois o movimento foi incorporado pelo mercado musical e pela crítica especializada.

Inicialmente a segunda parte do livro desenvolve uma comparação entre o Manifesto do Centro Popular de Cultura (Brasil) e o Manifiesto Del Nuevo Cancionero (Argentina). O objetivo foi de através de tais documentos, entendidos como veículos de expressão/divulgação de um projeto artístico-político-social, perceber as semelhanças e diferenças na arte de esquerda produzida nos anos 1960. Partindo da hipótese que um manifesto é uma forma de articular arte e política, um "instrumento de mobilização e transformação social” (GARCIA, 2021, p. 154), a autora discute os projetos defendidos por artistas na Argentina e no Brasil em torno da construção de uma identidade nacional-popular. Com relação ao caso argentino, percebe-se ainda a semelhança de alguns pontos dessa defesa com a Nova Canção Chilena e a Nova Canção Uruguai, afirmando que nos três existia um esforço de defesa da unidade latino-americana. A defesa pela unidade do continente, entretanto, não foi tomada como projeto principal no documento brasileiro, mesmo que tematizassem aspectos comuns as esquerdas vizinhas.

Para analisar o cenário da década de 1970, Garcia desenvolve dois estudos de caso. Tomando o Brasil como "palco" de sua análise, discute as trajetórias do grupo Taracón e do músico Abílio Manoel, artistas que mobilizaram em suas trajetórias ideias de integração latinoamericanas em meio ao contexto ditatorial brasileiro. A partir das trajetórias, Garcia mobiliza os repertórios destes artistas junto a publicações na imprensa e entrevistas concedidas a autora para tentar reconstruir as trajetórias artísticas de Abílio Manoel e o Taracón, possibilitando entender o lugar destes sujeitos por vezes apagados na música popular brasileira, assim como seus projetos. Destaca-se, neste estudo, a busca por demonstrar o estabelecimento de redes e 
Fronteiras - Revista Catarinense de História | https://periodicos.uffs.edu.br/index.php/FRCH/index

influências da música latino-americana no Brasil através das trajetórias ao perceber a construção do repertório e os motivos que levaram, por vezes, o cantor e a banda a escaparem dos olhos da censura. Apesar do Brasil servir como "palco" nestes estudos de caso, a análise da autora concentra-se na circulação midiática e espacial destes artistas, demonstrando seu papel na popularização dos ritmos latinos dentro do país e os processos de colaboração estabelecidos.

Ao longo de Do folclore à Militância: A canção latino-americana no século XX, Tânia Costa Garcia procura mapear os caminhos da canção de matriz folclórica no Brasil, Argentina e Chile, percebendo seus usos e presenças na canção militante. Tomando como recorte temporal o período entre 1940 e 1960, a autora discute as transformações e/ou atuações de cancioneiros populares como representantes de identidades nacionais inventadas, demonstrando o papel dos meios de comunicação, as políticas culturais nacionais e dos próprios sujeitos na construção das representações de nação. A ideia de tradição, que em alguns países como no Chile flertam com a ideia de autenticidade, perpassa toda a sua análise, assim como a atuação das próprias indústrias culturais no estabelecer o que poderia ou não considerado popular, sendo este um dos motivos que levou o folclore no Brasil a não ter espaço na música comercial midiática.

A obra pode ser inserida dentro de uma nova perspectiva historiográfica (GONZÁLEZ, 2016; NAPOLITANO, 2015) problematiza as canções enquanto "processos" que se desenvolvem entre produção, performance e contexto, mobilizando elementos sonoros, sensoriais e midiáticos, não somente em uma "temporalidade", mas que dialoga com distintas cotemporalidades, usos do passado e representações/ressignificações de experiências no presente e para o tempo vivido. A proposta metodológica, que articula mídias, artes e trajetórias com os planos políticos, culturais e sociais, certamente faz do novo livro de Tânia Costa Garcia uma referência fundamental a todos/as historiadores/as que decidam se envolver não somente no campo da música latino-americana, mas apresenta uma possibilidade metodológica ímpar aos estudos da História da Canção em perspectiva comparada.

\section{Referências bibliográficas}

GONZÁLEZ, Juan Pablo. Pensando a música a partir da América Latina. São Paulo: Letra e Voz, 2016.

NAPOLITANO, Marcos. História \& música. 3. ed. rev. Belo Horizonte: Autêntica, 2016.

\section{Agradecimento}

Este trabalho contou com financiamento da Coordenação de Aperfeiçoamento de Pessoal de Nível Superior - Brasil (CAPES) - Código de Financiamento 001. 
Fronteiras - Revista Catarinense de História | https://periodicos.uffs.edu.br/index.php/FRCH/index ISSN 2238-9717 | n. 37, p. 291-296, jul.-dez./2021 | DOI: https://doi.org/10.36661/2238-9717.2021n37.12351

Recebido em 22/04/2021. Aceito em 01/06/2021. 